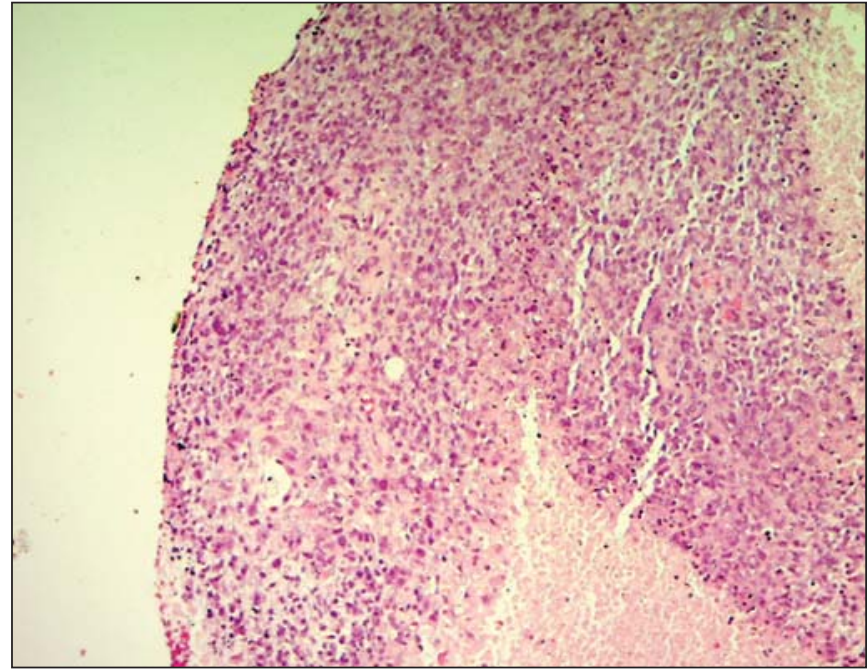

Figure 2. Undifferentiated sarcoma. Hematoxylin-eosin staining $(\times 100)$.

mass to an intravascular mass or even a solitary pulmonary nodule $^{(8)}$.

In the case reported here, the patient was young, had no comorbidities, and presented with a voluminous mass in the right intrathoracic right region, the initial diagnostic suspicion pointing to sarcoma.

In accordance with the literature, the analysis of clinical data and CT images obtained can only suggest primary sarcoma of the thorax as one of the differential diagnoses; the differentiation between sarcoma subtypes is only possible through pathological examination of the biopsy sample ${ }^{(8)}$.
Therefore, although it is a rare neoplasm, primary sarcoma must be considered among the diagnoses of thoracic tumors, especially when a large heterogeneous mass is identified in a young patient without evidence of malignancy in another part of the body.

\section{REFERENCES}

1. Batista MN, Barreto MM, Cavaguti RF, et al. Pulmonary artery sarcoma mimicking chronic pulmonary thromboembolism. Radiol Bras. 2015;48 $333-4$.

2. Nascif RL, Antón AGS, Fernandes GL, et al. Leiomyosarcoma of the inferior vena cava: a case report. Radiol Bras. 2014;47:384-6.

3. Teixeira VL, Santana Júnior PJ, Teixeira KISS, et al. Gastric Kaposi's sarcoma. Radiol Bras. 2015;48:196-7.

4. Alkis N, Muallaoglu S, Koçer M, et al. Primary adult soft tissue sarcomas: analysis of 294 patients. Med Oncol. 2011;28:391-6.

5. Hsu PK, Hsu HS, Lee HC, et al. Management of primary chest wall tumors: 14 years' clinical experience. J Chin Med Assoc. 2006;69:377-82.

6. Giaj Levra M, Novello S, Scagliotti GV, et al. Primary pleuropulmonary sarcoma: a rare disease entity. Clin Lung Cancer. 2012;13:399-407.

7. Tzias D, Cassidy HJ, Douraghi-Zadeh D, et al. Imaging characteristics of thoracic sarcomas - an illustration of interesting cases. ECR. 2013/ C-1007.

8. Gladish GW, Sabloff BM, Munden RF, et al. Primary thoracic sarcomas. Radiographics. 2002;22:621-37.

Carlos Henrique Simões de Oliveira Waszczynskyi ${ }^{1}$, Marcos Duarte Guimarães ${ }^{2}$, Luiz Felipe Sias Franco ${ }^{1}$, Bruno Hochhegger $^{3}$, Edson Marchiori ${ }^{4}$

1. Hospital Heliópolis, São Paulo, SP, Brazil. 2. A.C.Camargo Cancer Center e Hospital Heliópolis, São Paulo, SP, Brazil. 3. Universidade Federal de Ciências da Saúde de Porto Alegre (UFCSPA), Porto Alegre RS, Brazil. 4. Universidade Federal do Rio de Janeiro (UFRJ), Rio de Janeiro, RJ, Brazil. Mailing address: Dr. Carlos Henrique Simões de Oliveira Waszczynskyi. Hospital Heliópolis. Rua Cônego Xavier, 276, Nova Heliópolis. São Paulo, SP, Brazil, 04231-902. E-mail: lotd1104@hotmail.com.

http://dx.doi.org/10.1590/0100-3984.2015.0165

\title{
Tuberculosis: tracheal involvement
}

\section{Dear Editor,}

A previously healthy 22-year-old female sought medical attention, complaining of productive cough and hoarseness. She reported no other respiratory or constitutional symptoms. Physical examination revealed discrete stridor. For diagnostic clarification, computed tomography (CT) of the chest was performed The CT scan showed grouped, branching centrilobular opacities, with the "tree-in-bud" aspect, suggesting distal bronchiolar filling. The trachea and left main bronchus presented irregular internal contours, with nodular thickening of the walls (Figure 1), together with a discrete increase in the density of the mediastinal fat adjacent to those changes. Sputum examination was conducted and was positive for tuberculosis, confirming the clinical and radiological suspicion of tracheobronchial tuberculosis. Specific treatment was started and resulted in resolution of the findings.

In patients with tuberculosis, tracheal involvement is relatively uncommon, occurring in only $4 \%$ of those with the endobronchial form of the disease $\mathrm{e}^{(1-3)}$. Tracheobronchial tuberculosis mainly affects younger, female patients, its incidence peaking in the third decade of life. The disease can affect the greater part of the trachea, also affecting the bronchi, or it can affect just a small segment of the trachea or of one bronchus ${ }^{(4,5)}$. The clinical presentation can be insidious, simulating bronchogenic carcinoma, or acute, with a profile similar to that of asthma, foreign body aspiration, or pneumonia. In most cases, patients with tracheobronchial tuberculosis present a productive cough, hemoptysis, chest pain, generalized weakness, fever, dyspnea and bronchorrhea ${ }^{(1,3)}$. In cases that

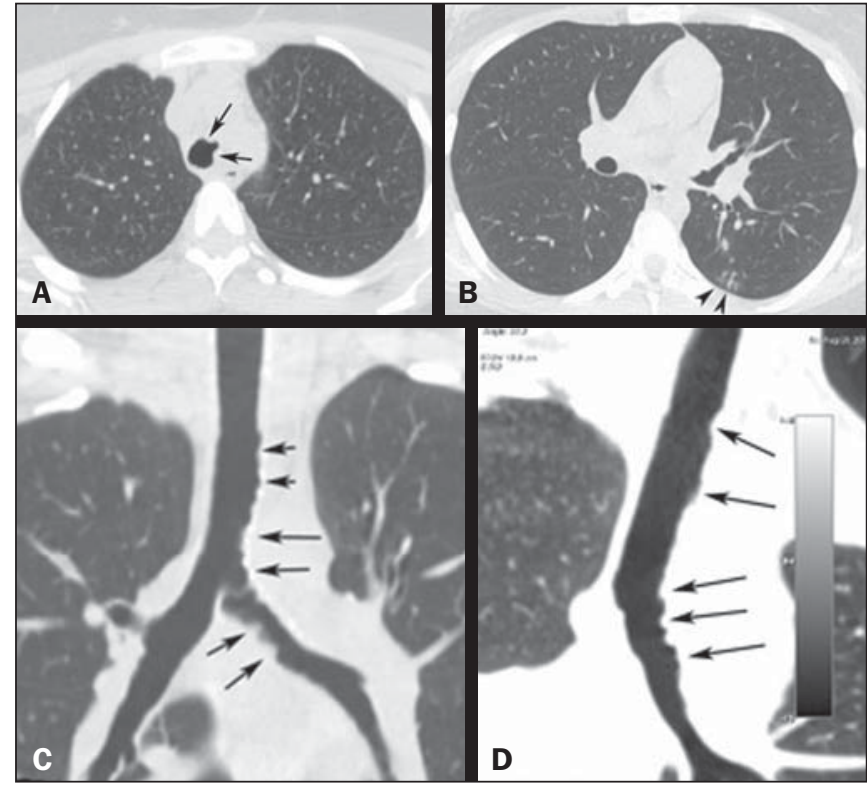

Figure 1. A: Axial CT slice showing irregular narrowing of the tracheal lumen (arrows). B: Axial CT slice showing centrilobular opacities, with a tree-in-bud aspect, in the lower lobe of the left lung, suggesting bronchiolar filling. C,D: Coronal and oblique coronal reconstructions showing irregular internal contours, together with parietal thickening (arrows), in the trachea and the left main bronchus.

are more severe, there can be acute tracheal obstruction ${ }^{(6)}$. The main complications are fibrotic scarring and tracheobronchial stenosis, an accurate diagnosis and early treatment being crucial $^{(6)}$. 
The differential diagnoses include other diseases affecting the trachea, not only those presenting localized involvementsuch as primary tracheal neoplasms, injuries of traumatic origin, and some infectious diseases-but also those presenting diffuse involvement-amyloidosis, tracheobronchopathia osteochondroplastica, relapsing polychondritis, laryngotracheobronchial papillomatosis, tracheobronchomegaly, neurofibromatosis, Wegener's granulomatosis, lymphoma, and paracoccidioidomycosis ${ }^{(5,7-12)}$.

Imaging studies have become increasingly important in the evaluation of chest diseases, as recently noted in the radiology literature of Brazil ${ }^{(13-19)}$. In the study of the trachea, imaging studies comprise X-rays and, primarily, CT of the chest, which can show irregular, circumferential narrowing of the lumen, with or without mediastinitis. In fibrotic disease, the lumen is smoother and the wall is not thickened. Lymphadenopathy is generally associated with active tuberculosis ${ }^{(4,6)}$.

Bronchoscopy can reveal inflamed mucosa, submucosal granuloma or polyp, ulceration, hypertrophy, or cicatricial stenosis; histologically, tracheobronchial tuberculosis can be identified the presence of giant cell granuloma and caseous necro$\operatorname{sis}^{(1)}$. Although the gold standard for the diagnosis of tracheobronchial tuberculosis is the finding of granulomas in the tracheal/bronchial mucosa, a diagnosis based on imaging findings and sputum positivity is accepted and enables immediate treatment $^{(2)}$.

Making a diagnosis of tracheobronchial tuberculosis requires suspicion, and it is necessary to correlate the clinical manifestations with the radiological findings. Early diagnosis and treatment can avert the complications of the disease.

\section{REFERENCES}

1. Lee JH, Park SS, Lee DH, et al. Endobronchial tuberculosis. Clinical and bronchoscopic features in 121 cases. Chest. 1992;102:990-4.

2. Morrone N, Abe NS. Bronchoscopic findings in patients with pulmonary tuberculosis. J Bronchol. 2007;14:15-8.

3. Arora A, Bhalla AS, Jana M, et al. Overview of airway involvement in tuberculosis. J Med Imaging Radiat Oncol. 2013;57:576-81.

4. Moon WK, Im JG, Yeon KM, et al. Tuberculosis of the central airways: CT findings of active and fibrotic disease. AJR Am J Roentgenol. 1997;169:649-53.

5. Marchiori E, Pozes AS, Souza Jr AS, et al. Alterações difusas da traqueia: aspectos na tomografia computadorizada. J Bras Pneumol. 2008;34:4754.
6. Smati B, Boudaya MS, Ayadi A, et al. Tuberculosis of the trachea. Ann Thorac Surg. 2006;82:1900-1.

7. Gasparetto TD, Azevedo FB, Toledo A, et al. Primary tracheal nonHodgkin lymphoma: case report with an emphasis on computed tomography findings. J Thorac Imaging 2010;25:W24-6.

8. Marchiori E, Zanetti G, Mano CM. Tracheobronchial papillomatosis with diffuse cavitary lung lesions. Pediatr Radiol. 2010;40:1301-2.

9. Marchiori E, Araujo Neto C, Meirelles GSP, et al. Laryngotracheobronchial papillomatosis: findings on computed tomography scans of the chest. J Bras Pneumol. 2008;34:1084-9.

10. Marchiori E, Escuissato DL, Souza Jr AS, et al. Computed tomography findings in patients with tracheal paracoccidioidomycosis. J Comput Assist Tomogr. 2008;32:788-91.

11. Azeredo F, Severo A, Zanetti G, et al. Floppy ears and tracheal wall narrowing. Neth J Med. 2012;70:417-21.

12. Hochhegger B, Guimarães MD, Marchiori E. Thacheal paraganglioma: differential diagnosis of a contrast-enhanced tracheal mass. AJR Am J Roentgenol. 2014;202:w598.

13. Lachi T, Nakayama M. Radiological findings of pulmonary tuberculosis in indigenous patients in Dourados, MS, Brazil. Radiol Bras. 2015; $48: 275-81$.

14. Barbosa BC, Marchiori E, Zanetti GMR, et al. Catamenial pneumothorax. Radiol Bras. 2015;48:128-9.

15. Francisco FAF, Rodrigues RS, Barreto MM, et al. Can chest highresolution computed tomography findings diagnose pulmonary alveolar microlithiasis? Radiol Bras. 2015;48:205-10.

16. Guimaraes MD, Hochhegger B, Koenigkam-Santos M, et al. Magnetic resonance imaging of the chest in the evaluation of cancer patients: state of the art. Radiol Bras. 2015;48:33-42.

17. Batista MN, Barreto MM, Cavaguti RF, et al. Pulmonary artery sarcoma mimicking chronic pulmonary thromboembolism. Radiol Bras. 2015; 48:333-4.

18. Guimarães MD. Pulmonary tuberculosis in Brazilian indians: a picture of this context depicted through radiography. Radiol Bras. 2015;48(5): $\mathrm{v}-\mathrm{vi}$.

19. Silva Junior GM, Zanetti GMR, Barillo JL, et al. Peripheral primitive neuroectodermal tumor of chest wall in young adult. Radiol Bras. 2015;48:59-60.

\section{Brainner Campos Barbosa ${ }^{1}$, Viviane Brandão Amorim ${ }^{2}$,} Luiz Flávio Maia Ribeiro ${ }^{2}$, Edson Marchiori ${ }^{3}$

1. Hospital Samaritano - Clínica Luiz Felippe Mattoso, Rio de Janeiro, RJ, Brazil. 2. Clínica Felippe Mattoso, Rio de Janeiro, RJ, Brazil. 3. Universidade Federal do Rio de Janeiro (UFRJ), Rio de Janeiro, RJ, Brazil. Mailing address: Dr. Brainner Campos Barbosa. Rua das Laranjeiras, 371, ap. 303, Laranjeiras. Rio de Janeiro, RJ, Brazil, 22240004. E-mail: brainnerc@gmail.com.

http://dx.doi.org/10.1590/0100-3984.2015.0200

\section{Immune reconstitution inflammatory syndrome, with pulmonary} and neurological cryptococcosis, in an HIV-negative patient

\section{Dear Editor,}

A 26-year-old male presented with complaints of cough and fever for a few days. He reported having followed a weight loss program for the last four months, having lost $20 \mathrm{~kg}$. He reported no comorbidities.

Chest X-ray showed pulmonary consolidation in the left lung. A complete blood count showed leukocytosis and a lymphocyte count at the lower limit of normality. Subsequent X-rays, during antibiotic therapy, showed an increase in the consolidation. Computed tomography of the chest showed left lung consolidation with air bronchogram and a partially rounded hilar opacity, both containing areas of hypointense signals (Figure 1A), raising the hypothesis of an infectious or neoplastic process. Because he developed mental confusion, seizures, and postural instability, the patient was submitted to magnetic resonance imaging (MRI) of the brain, which showed multiple intraparenchymal cystic lesions (Figure 1B), with no enhancement and minimal edema at the borders.

Pathological examination of a biopsy sample obtained from the pulmonary consolidation revealed fungal infection with characteristics of deep cryptococcal mycosis. Staining with mucicarmine showed a mucin-positive capsule. The serology was negative for HIV, as well as for hepatitis B and C. Treatment was started with fluconazole, alternated with amphotericin B. During hospitalization, the general status of the patient became unstable and he was submitted to tracheostomy, subsequently developing tracheal candidiasis. After clinical improvement, he was discharged to outpatient follow-up, with home therapy and attention to an appropriate diet.

Five weeks after discharge, the patient was readmitted to the hospital with worsening neurological status. Another MRI of the brain showed the development of marked, progressive perilesional vasogenic edema (Figure 1C) and significant enhancement of 